\title{
Growth of Thiobacillus A2 under Alternating Growth Conditions in the Chemostat
}

\author{
By JAN C. GOTTSCHAL, † HENK J. NANNINGA AND \\ J. GIJS KUENEN*‡ \\ Laboratorium voor Microbiologie, Biologisch Centrum, Universiteit Groningen, \\ Kerklaan 30,9751 NN Haren, The Netherlands
}

(Received 18 December 1980; revised 11 March 1981)

\begin{abstract}
A chemostat culture of Thiobacillus A2 was grown under alternate limitation of acetate and thiosulphate at a dilution rate of $0.05 \mathrm{~h}^{-1}$. With a substrate alternation of $4 \mathrm{~h}$ acetate $/ 4 \mathrm{~h}$ thiosulphate or $8 \mathrm{~h}$ acetate $/ 16 \mathrm{~h}$ thiosulphate, uninterrupted growth of the culture was obtained. However, with $16 \mathrm{~h}$ acetate $/ 8 \mathrm{~h}$ thiosulphate, Thiobacillus A2 required several hours before it attained autotrophic growth at a rate of $0.05 \mathrm{~h}^{-1}$ following the transition from acetate to thiosulphate supply. In a two-membered mixed culture with the heterotrophic spirillum G7, Thiobacillus A2 outcompeted the heterotroph when grown under alternating limitation of acetate $(4 \mathrm{~h})$ and thiosulphate $(4 \mathrm{~h})$. Under the same growth conditions Thiobacillus A2 coexisted in equal numbers with Thiobacillus neapolitanus, from which it was concluded that Thiobacillus A2 grew only heterotrophically on acetate in this case. Analogous competition experiments with three-membered cultures, grown under the same conditions, resulted in complete elimination of Thiobacillus A2 and coexistence of $T$. neapolitanus and spirillum G7 in equal numbers. In an enrichment culture, again grown under the same regime, a facultatively chemolithotrophic spirillum-shaped Thiobacillus or Thiomicrospira became dominant; this organism was subsequently isolated in pure culture.
\end{abstract}

\section{INTRODUCTION}

In previous studies on the ecophysiology of the facultatively chemolithotrophic Thiobacillus A2 it was demonstrated that part of the ecological niche of a Thiobacillus A2-like organism might be its capacity to thrive well under conditions of a continuous supply of mixtures of organic energy sources and reduced sulphur compounds (Gottschal et al., 1979; Gottschal \& Kuenen, $1980 a, b$; Smith \& Kelly, 1979).

As suggested earlier (Gottschal et al., 1979), an additional advantage of the facultative chemolithotrophs over the specialized obligate chemolithotrophs might be their metabolic flexibility, allowing them to grow alternately autotrophically and heterotrophically. Results from recent experiments (Gottschal et al., 1981) on this particular aspect of the metabolism of Thiobacillus A2 demonstrated that a rapid change-over from heterotrophic to autotrophic growth was indeed possible, provided the potential to metabolize the inorganic energy source (thiosulphate) was still available. Furthermore, it was shown that both this potential and the capacity to fix $\mathrm{CO}_{2}$ decreased fairly rapidly during heterotrophic growth. In contrast, the capacity to metabolize the organic substrate (acetate) was retained to a considerable extent, even after prolonged autotrophic growth on thiosulphate. Thus Thiobacillus A2 can only profit optimally from conditions which allow alternate autotrophic and heterotrophic growth when the duration of the period of heterotrophic growth is not too long. A further prerequisite

† Present address: Department of Botany and Microbiology, University College of Wales, Aberystwyth SY23 3DA, U.K.

‡ Present address: Laboratorium voor Microbiologie, Technische Universiteit Delft, Julianalaan 67A, 2628BC Delft, The Netherlands.

0022-1287/81/0000-9694\$02.00 (C) 1981 SGM 
for successful competition with more specialized heterotrophs and chemolithotrophs under alternating conditions would be that Thiobacillus A2 resumes growth following a substrate transition at least as rapidly as its competitors in a mixed culture.

In the present study we focused first on pure chemostat cultures of Thiobacillus A2 grown under various regimes of substrate alternation at a constant dilution rate in order to establish alternating conditions permitting uninterrupted growth of Thiobacillus A2. Subsequent competition experiments with mixed cultures composed of Thiobacillus A2 and the obligate chemolithotroph Thiobacillus neapolitanus and the heterotrophic spirillum G7 were performed to investigate whether the growth conditions thus selected might indeed allow Thiobacillus A2 to compete successfully with its competitors. In a final chemostat enrichment experiment it was explored whether an alternate supply of acetate and thiosulphate might lead to the selective enrichment of facultative chemolithotrophic organisms from a freshwater habitat.

\section{METHODS}

Organisms. The organisms used in this study-the facultatively chemolithotrophic Thiobacillus A2, the heterotrophic spirillum G7 and the obligately chemolithotrophic Thiobacillus neapolitanus-have been described previously (Taylor \& Hoare, 1969; Gottschal et al., 1979).

Media. The basal medium used in the chemostat cultures contained (in deionized water; \%, w/v): $\mathrm{K}_{2} \mathrm{HPO}_{4}$, $0.08 ; \mathrm{KH}_{2} \mathrm{PO}_{4}, 0.03 ; \mathrm{MgSO}_{4} .7 \mathrm{H}_{2} \mathrm{O}, 0.04 ; \mathrm{NH}_{4} \mathrm{Cl}, 0.04$; plus a trace elements solution (Vishniac \& Santer, 1957) at $2 \mathrm{ml} \mathrm{l}^{-1}$. The trace elements solution contained $2.2 \mathrm{~g}$ instead of the originally reported $22 \mathrm{~g} \mathrm{ZnSO}_{4} \cdot 7 \mathrm{H}_{2} \mathrm{O}^{-1}$. In the medium used in the enrichment experiment vitamin $B_{12}$ and biotin were added to final concentrations of $15 \mu \mathrm{g}$ $1^{-1}$ and $10 \mu \mathrm{g}^{-1}$, respectively. Different amounts of sodium acetate and/or sodium thiosulphate were added to the medium as indicated in Results. The medium was sterilized by autoclaving for $30 \mathrm{~min}$ at $118^{\circ} \mathrm{C}$. The solidified media used in plate counting were prepared as described above, the only difference being that yeast extract $(0.005 \%, \mathrm{w} / \mathrm{v})$ and agar $(1.5 \%, \mathrm{w} / \mathrm{v})$ were added.

Growth conditions. The continuous culture equipment used has been described by Harder et al. (1974) and Kuenen \& Veldkamp (1973). Cultures were maintained at $28^{\circ} \mathrm{C}$ at a pH of 7.5 , by automatic addition of 1 $\mathrm{M}-\mathrm{Na}_{2} \mathrm{CO}_{3}$ or $1 \mathrm{M}-\mathrm{HCl}$, depending on the substrate used. The oxygen concentration in the cultures was continuously monitored by means of a Mackereth-type oxygen electrode; it ranged between 50 and $90 \%$ air saturation. Transitions from one medium to another were done automatically by timed switching of the two pumps feeding the medium to the culture.

Viability and cell discrimination. Viability was measured on appropriate agar media by the method of Postgate (1969). The organisms were counted separately on three different agar media: acetate $(5 \mathrm{mM})$ plus yeast extract $(0.05 \%)$, acetate $(5 \mathrm{mM})$ plus thiosulphate $(10 \mathrm{mM})$; thiosulphate $(10 \mathrm{mM})$. Cell counting was done using three different culture dilutions from which five $0.10 \mathrm{ml}$ portions were spread on each of the three agar media.

Miscellaneous methods. Oxygen consumption rates, thiosulphate and acetate concentrations and cell density (measured as organic cell carbon) were determined as described by Gottschal et al. (1979). $\mathrm{CO}_{2}$ fixation rates by whole cells were measured according to Gottschal \& Kuenen $(1980 \mathrm{~b})$, using $\left[{ }^{14} \mathrm{C}\right]$ bicarbonate. Protein was measured by the Lowry method.

Chemicals. All chemicals used were of analytical grade and were obtained from Merck or BDH.

\section{RESULTS}

\section{Alternating autotrophic and heterotrophic growth of Thiobacillus A2 in the chemostat}

Thiobacillus A2 was grown mixotrophically under thiosulphate and acetate limitation in the chemostat at a dilution rate $(D)$ of $0.05 \mathrm{~h}^{-1}$ with substrate concentrations in the reservoir medium of $20 \mathrm{~mm}$-thiosulphate and $5 \mathrm{mM}$-acetate. After approximately $2 \mathrm{~d}$ the reservoir medium was replaced by two different media, one containing thiosulphate $(40 \mathrm{mM})$ and the other acetate $(10 \mathrm{mM})$, which were subsequently supplied intermittently to the chemostat culture. Since an alternate supply of thiosulphate and acetate required a rapid change-over from autotrophic to heterotrophic metabolism, in order to allow uninterrupted growth the dilution rate was first reduced to approximately $0.02 \mathrm{~h}^{-1}$ and then gradually increased to $0.05 \mathrm{~h}^{-1}$ in order for the culture to adapt to the new growth conditions. Some basic properties 


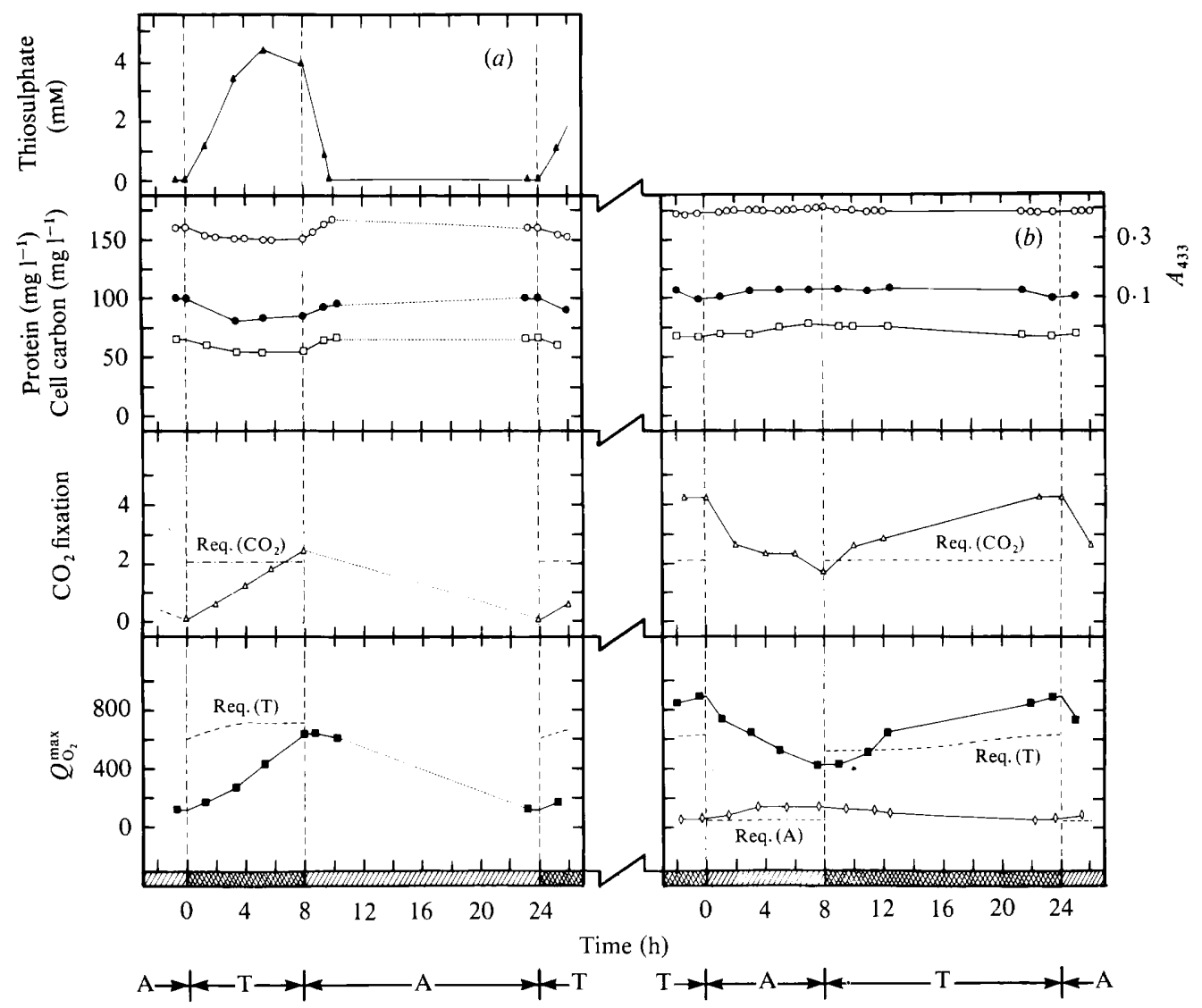

Fig. 1. Characteristics of Thiobacillus A2 grown under alternate limitation of acetate (A) and thiosulphate $(T)$ in continuous culture at a dilution rate of $0.05 \mathrm{~h}^{-1}$. The inflowing medium contained either $10 \mathrm{~mm}$-acetate or $40 \mathrm{~mm}$-thiosulphate: (a) thiosulphate limitation during $8 \mathrm{~h}$ and acetate limitation during $16 \mathrm{~h} ;(b)$ thiosulphate limitation during $16 \mathrm{~h}$ and acetate limitation during $8 \mathrm{~h}$. $\mathrm{O}$, Absorbance $\left(A_{433}\right)$;, protein content; $\square$, cell carbon content; $\triangle$, rate of $\mathrm{CO}_{2}$ fixation by whole cells $\left[\mu \mathrm{mol} \mathrm{CO} \mathrm{CO}_{2} \mathrm{~h}^{-1}\left(\mathrm{mg}\right.\right.$ dry wt) $\left.{ }^{-1}\right] ; \mathbf{\square}$, potential oxidation rate $\left(Q_{\mathrm{O}_{2}}^{\max }\right)$ for thiosulphate $\left[\mu \mathrm{O}_{2} \mathrm{~h}^{-1}(\mathrm{mg}\right.$ dry $\left.w t)^{-1}\right] ; \diamond, Q_{0_{2}}^{\max }$ for acetate $\left[\mu \mathrm{O}_{2} \mathrm{~h}^{-1}(\mathrm{mg} \text { dry wt })^{-1}\right]$. The oxidation rates required for complete oxidation of the acetate and thiosulphate supplied to the chemostat (see text) are indicated by the lines labelled Req. (A) and Req. (T) respectively. Req. $\left(\mathrm{CO}_{2}\right)$ indicates the $\mathrm{CO}_{2}$ fixation rate required for autotrophic growth at a rate of $0.05 \mathrm{~h}^{-1}$.

of the culture were measured when it had reached a situation characterized by identical repetition of changes in the cell density, rate of oxygen consumption and capacity to fix bicarbonate and to oxidize thiosulphate. When growth had become balanced in this manner the culture was assumed to be in a 'pseudo-steady state'. This state was usually obtained after five to eight volume changes.

In the first experiment a regime of substrate addition was chosen which allowed autotrophic growth during $8 \mathrm{~h}$, followed by heterotrophic growth during a period of $16 \mathrm{~h}$, then again autotrophic growth during $8 \mathrm{~h}$, and so on. The results presented in Fig. $1(a)$ are typical for cultures at pseudo-steady state growing under this regime of substrate addition. It was observed that the absorbance $\left(A_{433}\right)$, and the protein content and carbon content of the culture dropped during several hours following the change-over $(t=0)$ from heterotrophic growth (acetate) to autotrophic growth (thiosulphate). Since the yield of Thiobacillus A2 on $40 \mathrm{~mm}$-thiosulphate is similar to that on $10 \mathrm{mM}$-acetate (Gottschal \& Kuenen, $1980 \mathrm{~b}$ ), this 
indicated that the growth rate during the initial period was less than the dilution rate of 0.05 $\mathrm{h}^{-1}$. This phenomenon is most probably explained by the observation that the 'autotrophic potential' (i.e. the potential rate of $\mathrm{CO}_{2}$ fixation and thiosulphate oxidation together) was low, and insufficient to support growth at a specific rate of $0.05 \mathrm{~h}^{-1}$ at the moment of the change-over. Actually, it could be calculated that the required rate of $\mathrm{CO}_{2}$ fixation was not reached until 7-8 $\mathrm{h}$ after the change-over, whereas the required rate of thiosulphate oxidation seemed not to be attained at all (Fig. 1 $a$ ). Somewhat contradictory to such calculations was the observation that the cell density of the culture became constant 5-6 h after the change-over, suggesting that the autotrophic potential was sufficient to permit growth at a specific rate of $0.05 \mathrm{~h}^{-1}$ by that time. This view was further supported by the fact that thiosulphate did not accumulate any further from that moment. This discrepancy is most probably explained by the fact that the actual activities in the culture were probably $15-25 \%$ higher than those measured in washed cell suspensions; this has been commonly observed during experiments with chemostat cultures of thiobacilli (J. G. Kuenen, unpublished results).

In contrast with the change-over at $t=0$, growth did not slow down when thiosulphate was replaced by acetate. Growth continued uninterrupted, even at a somewhat higher rate than $0.05 \mathrm{~h}^{-1}$. During the first $2 \mathrm{~h}$ after the shift to acetate the culture still contained some accumulated thiosulphate, which was utilized simultaneously with acetate. This result was consistent with earlier observations that thiosulphate-grown cells of Thiobacillus A2 were able to grow mixotrophically or heterotrophically without a lag, a finding which was explained by a high constitutive acetate respiration capacity (Gottschal \& Kuenen, $1980 \mathrm{~b}$; Gottschal et al., 1981). During the period of acetate supply $(t=8-24 \mathrm{~h})$, the autotrophic potential decreased again to the same level as detected at $t=0$.

It was obvious from the above results that the combination of a long period of heterotrophic growth $(16 \mathrm{~h})$ and a relatively short period of autotrophic growth $(8 \mathrm{~h})$ resulted in a loss of autotrophic potential too extensive to permit immediate autotrophic growth. In an attempt to find substrate-alternating conditions that allowed continued growth during both autotrophic and heterotrophic growth periods, a regime of substrate addition was applied which allowed autotrophic growth during $16 \mathrm{~h}$ and heterotrophic growth during $8 \mathrm{~h}$ (Fig. $1 \mathrm{~b}$ ). Very little change was observed in the cell density of the culture following the substrate transition and no accumulation of thiosulphate was detected after the change-over from acetate-limited to thiosulphate-limited growth. A comparison of the potential rate of $\mathrm{CO}_{2}$ fixation and thiosulphate oxidation, measured in washed cell suspensions, revealed that these capacities were, again, approximately $20-25 \%$ too low to enable a specific growth rate of $0.05 \mathrm{~h}^{-1}$ immediately following the change-over from acetate to thiosulphate limitation (Fig. $1 \mathrm{~b}$ ). Assuming once more that these capacities were underestimated by $15-25 \%$ (see above), the autotrophic potential would be just sufficient to allow uninterrupted growth. The potential rate of acetate oxidation in washed cell suspensions was also measured and its value could just about account for the required rate of acetate oxidation, if the assumption was made that $60 \%$ of the available acetate was oxidized and the remaining $40 \%$ was assimilated (Gottschal \& Kuenen, $1980 b$ ).

Though the substrate regime employed in the above experiments allowed uninterrupted growth at a specific rate of $0.05 \mathrm{~h}^{-1}$, the metabolic capacities to do so were barely sufficient, particularly during the transition from heterotrophic to autotrophic growth. Therefore experiments were performed to see whether a more frequent substrate alternation would provide conditions more favourable for uninterrupted growth of Thiobacillus A2. In Fig. 2 the results are presented of experiments in which every $4 \mathrm{~h}$ growth changed from autotrophic to heterotrophic or vice versa. The results clearly demonstrated that the culture could continuously grow at a rate of $0.05 \mathrm{~h}^{-1}$, as indicated by the observed constancy of the cell density.

As in the previous experiment (Fig. $1 b$ ), the substrate oxidation potential for both substrates and the potential rate of $\mathrm{CO}_{2}$ fixation were again just sufficient to ensure continued 


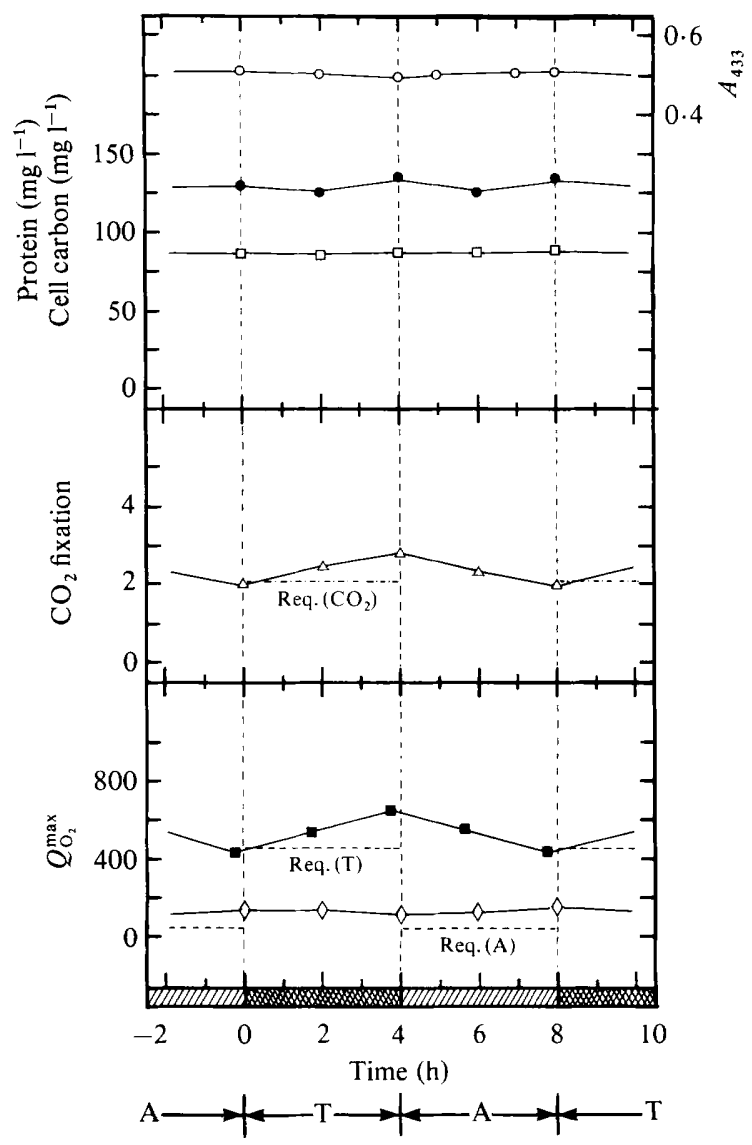

Fig. 2. Characteristics of Thiobacillus A2 grown under alternate limitation of acetate (A) and thiosulphate $(T)$ in continuous culture at a dilution rate of $0.05 \mathrm{~h}^{-1}$, with thiosulphate limitation during $4 \mathrm{~h}$ and acetate limitation during $4 \mathrm{~h}$. Other details as for Fig. 1.

growth at a rate of $0.05 \mathrm{~h}^{-1}$. A major difference between the two experiments was the observed $20 \%$ higher cell density in the latter experiment (compare Figs 2 and $1 b$ ). This difference in cell yield may be explained by the fact that growth in the last experiment was more balanced than in the previous one. As it was the aim of this study to investigate the competition between Thiobacillus A2, the heterotrophic spirillum G7, and the specialized chemolithotrophic Thiobacillus neapolitanus under similar conditions, the experiment was performed not only at $\mathrm{pH} 8.0$ but also at the $\mathrm{pH}$ of 7.5 which had to be used in the competition experiments (Gottschal et al., 1979). No significant differences were found at the two $\mathrm{pH}$ values.

\section{Competition between Thiobacillus $A 2$ and spirillum $G 7$ or Thiobacillus neapolitanus during alternating autotrophic and heterotrophic growth conditions}

Competition experiments between Thiobacillus A2 and a specialized heterotroph (spirillum G7) or chemolithotroph ( $T$. neapolitanus) were conducted in continuous culture in which growth was alternately limited by acetate or thiosulphate at a dilution rate of $0.05 \mathrm{~h}^{-1}$. Spirillum G7 is able to grow on acetate but is unable to metabolize thiosulphate, while $T$. neapolitanus can only grow autotrophically with thiosulphate as energy source and $\mathrm{CO}_{2}$ as the main source of carbon (Gottschal et al., 1979). Since an intermittent supply of acetate and thiosulphate implies alternation between growth and starvation for the two specialized 


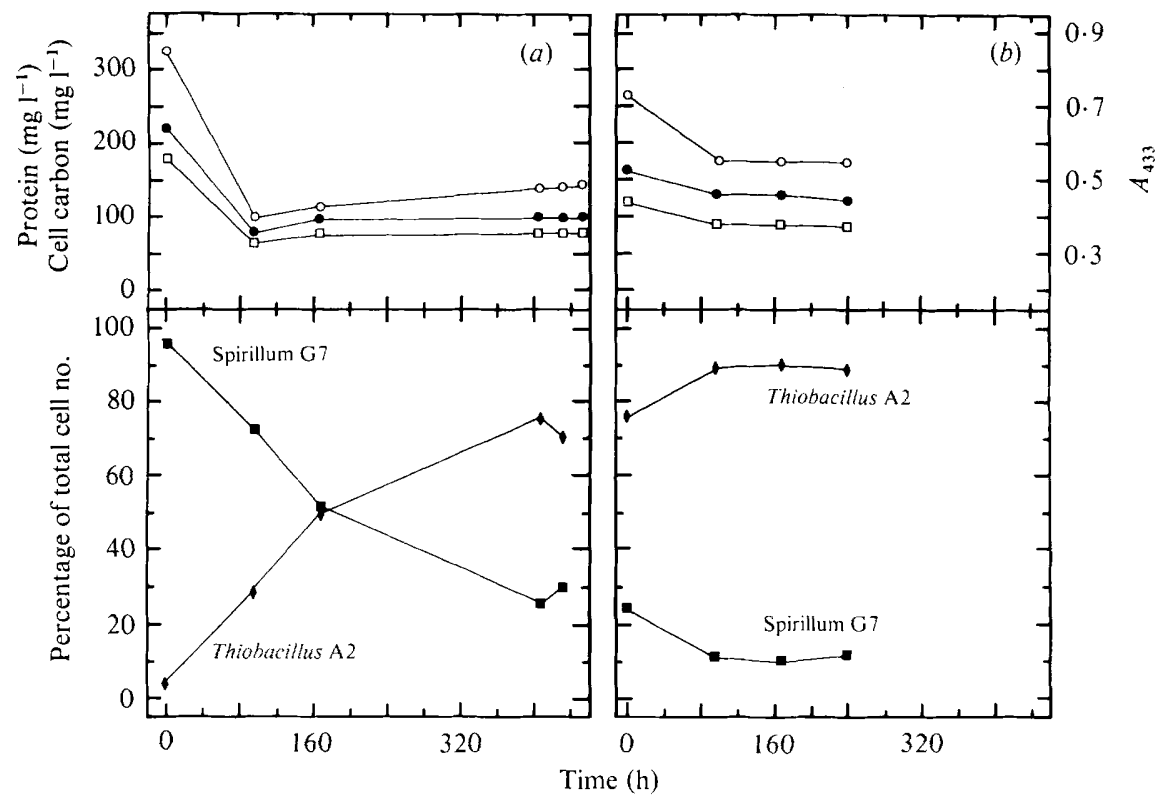

Fig. 3. Competition in continuous culture between Thiobacillus A2 ( $)$ and spirillum G7 ( $\square$ ) for thiosulphate and acetate as growth-limiting substrates supplied intermittently to the chemostat, each during $4 \mathrm{~h}$ (compare Fig. 2). The dilution rate was $0.05 \mathrm{~h}^{-1}$. The inflowing media contained either $10 \mathrm{~mm}$-acetate or $40 \mathrm{~mm}$-thiosulphate. The total cell number in the culture was $1.4-1.7 \times 10^{9}$ cells $\mathrm{m}^{-1}$. O, Absorbance $\left(A_{433}\right) ; 0$, protein content; $\square$, cell carbon content. Parts $(a)$ and $(b)$ represent identical experiments, except that a different initial ratio of Thiobacillus A2 and spirillum G7 was used.

organisms, the effect of such conditions on the growth of pure cultures of these organisms was investigated in preliminary experiments. It appeared that a substrate alternation which allowed growth during a period of $4 \mathrm{~h}$, followed by a starvation period of $4 \mathrm{~h}$, and so on, did not affect the potential rate of substrate oxidation of $T$. neapolitanus or spirillum G7. On the contrary, the cultures retained an overcapacity (two- to fourfold) over that required for complete oxidation of the substrate at the given dilution rate of $0.05 \mathrm{~h}^{-1}$. Furthermore, the changes observed in the cell density of such cultures clearly indicated that washout occurred during the period of starvation and that growth started immediately when the metabolizable substrate was supplied again.

The results are presented in Fig. 3 of two successive competition experiments between Thiobacillus A2 and spirillum G7 grown in a chemostat on acetate and thiosulphate which were supplied intermittently during periods of $4 \mathrm{~h}$ at a dilution rate of $0.05 \mathrm{~h}^{-1}$. The first experiment was started by the inoculation of the chemostat with a high cell number of spirillum G7 compared with that of Thiobacillus A2. After an initial period of unrestricted growth on a mixture of thiosulphate $(10 \mathrm{~mm})$ and acetate $(5 \mathrm{~mm})$ until both substrates had been consumed, intermittent feeding of the two substrates was started. The relative cell number of Thiobacillus A2 increased gradually and after 21 volume changes $(420 \mathrm{~h})$ this organism accounted for approximately $70 \%$ of the total cell number (Fig. $3 a$ ). Since at this time changes in the relative cell numbers were still observed, and because wall growth might become a factor which could no longer be neglected in the competition after such a long period of cultivation, a new culture was set up, this time with an initially low cell number of spirillum G7 relative to Thiobacillus A2. As can be judged from the relative cell number and the total cell density (Fig. $3 b$ ), the culture stabilized after a few volume changes (about $100 \mathrm{~h}$ ), with Thiobacillus A2 again being the dominant organism ( $90 \%$ of the total cell number). 


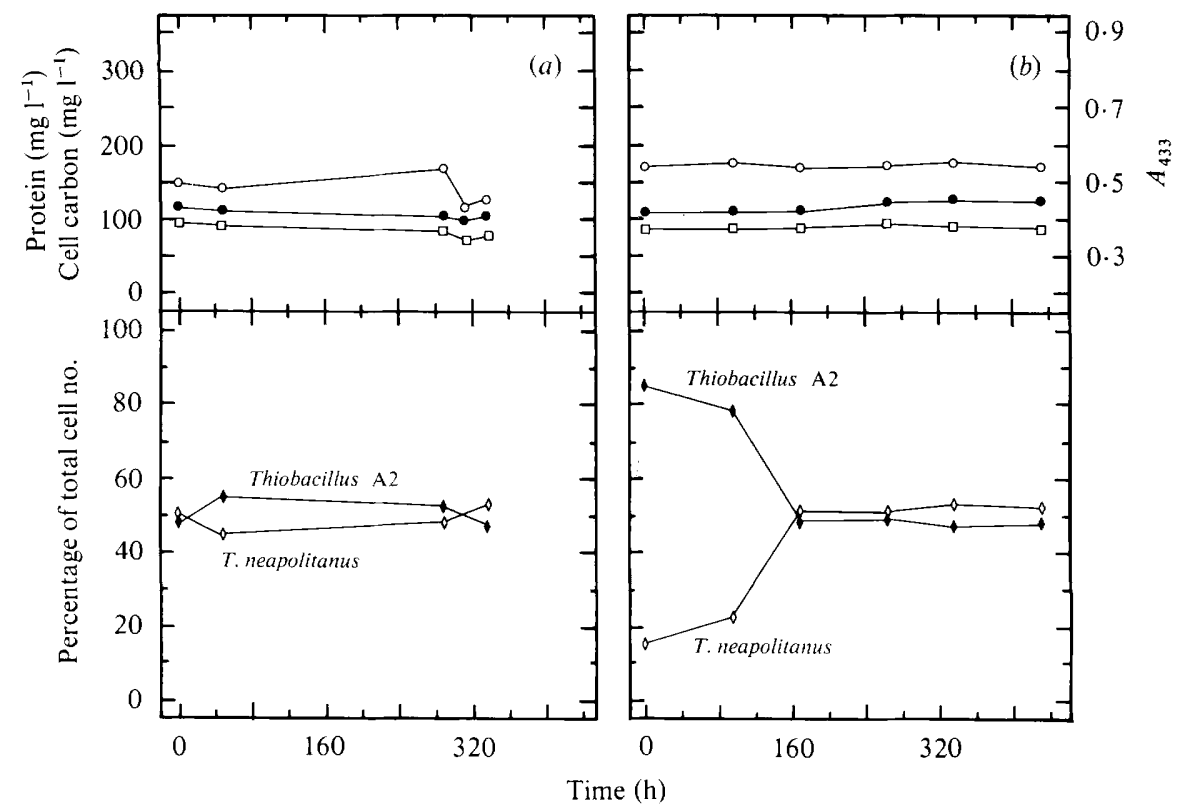

Fig. 4. Competition in continuous culture between Thiobacillus A2 $(\diamond)$ and $T$. neapolitanus $(\diamond)$ for thiosulphate and acetate as growth-limiting substrates supplied intermittently to the chemostat, each during $4 \mathrm{~h}$. The total cell number in the culture was $1.5-1.9 \times 10^{9}$ cells $\mathrm{ml}^{-1}$. Other details as for Fig. 3. Parts $(a)$ and $(b)$ represent identical experiments, except that a different initial ratio of Thiobacillus A2 and $T$. neapolitanus was used.

Analogous competition experiments were performed with two-membered mixed cultures of Thiobacillus A2 and the obligate chemolithotroph $T$. neapolitanus (Fig. 4). The first experiment (Fig. 4a) was started with equal cell numbers of Thiobacillus A2 and $T$. neapolitanus. Surprisingly little variation was observed in the cell density or in the numbers of the two organisms relative to each other during 16 volume changes $(320 \mathrm{~h})$. In order to exclude the possibility that this result was due to the initial ratio of the two species, the experiment was repeated with a high initial ratio of the number of Thiobacillus A2 cells relative to that of $T$. neapolitanus cells. From the result of this experiment (Fig. $4 b$ ) it could be concluded again that the two thiobacilli coexisted under the given growth conditions and that this result was independent of the initial composition of the population mixture. As will be discussed below, the observed coexistence is most probably explained by the fact that $T$. neapolitanus metabolized all the available thiosulphate and Thiobacillus A2 grew heterotrophically at the expense of acetate only.

\section{Competition between Thiobacillus A2, spirillum $G 7$ and Thiobacillus neapolitanus during alternating autotrophic and heterotrophic growth conditions}

Although the results of the above two-membered mixed culture experiments demonstrated that the facultatively chemolithotrophic thiobacillus could successfully compete with the heterotroph and also could coexist with the chemolithotroph, these results allowed no definite predictions of the outcome of a three-membered mixed culture experiment under similar substrate alternating conditions. The results of such an experiment (Fig. 5a), clearly demonstrated that Thiobacillus A2, initially present as the dominant species, was gradually outgrown by spirillum $\mathrm{G} 7$ and $T$. neapolitanus. The outcome of this experiment was in contrast with results reported in an earlier publication (Gottschal et al., 1979) in which a study was made of three-membered mixed cultures of the same species composition, but grown under simultaneous limitation of acetate and thiosulphate. It was shown there that 


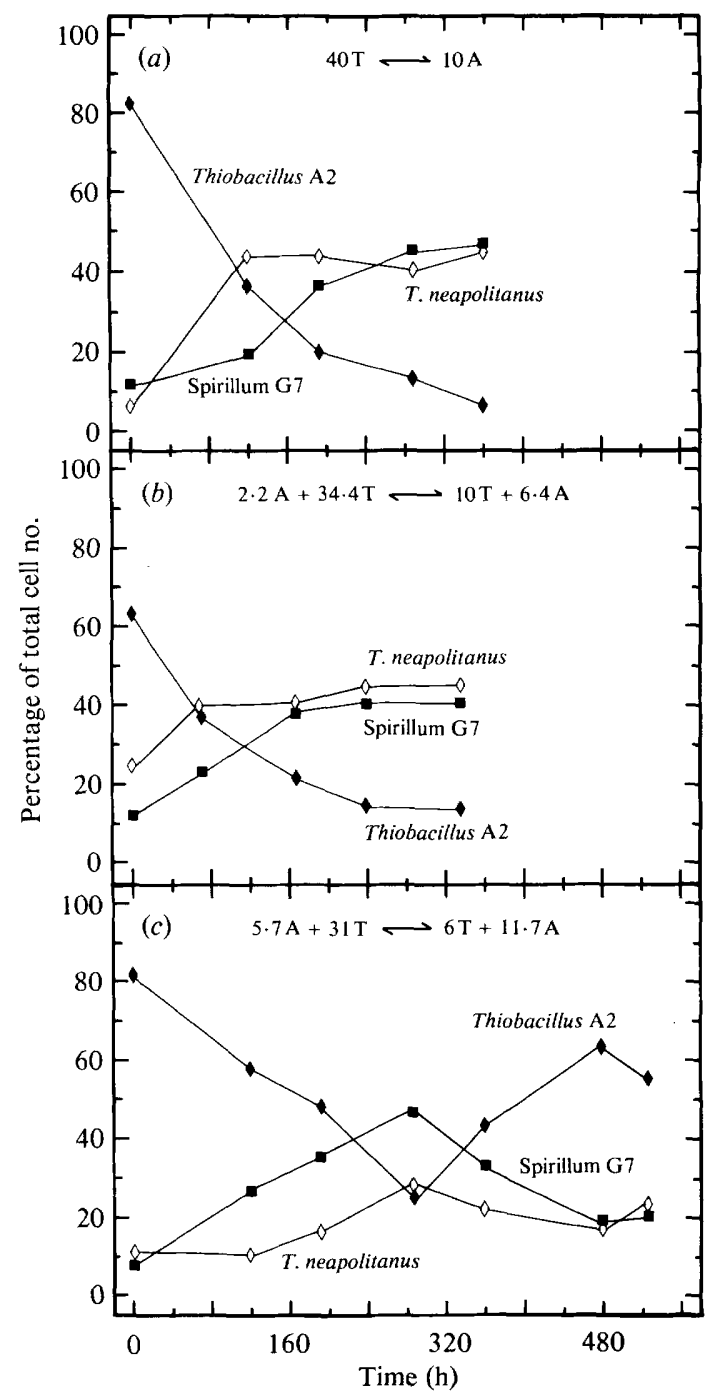

Fig. 5. Competition in continuous culture between Thiobacillus A2 ( $), T$. neapolitanus $(\diamond)$ and spirillum $G 7(\mathbb{D})$ for thiosulphate $(\mathrm{T})$ and acetate $(\mathrm{A})$ as growth-limiting substrates. The dilution rate was $0.05 \mathrm{~h}^{-1}$, with intermittent feeding of two media, containing either thiosulphate or acetate, or containing different combinations of thiosulphate and acetate; these pairs of media were supplied alternately to the culture, each during $4 \mathrm{~h}$. (a) One medium contained $10 \mathrm{~mm}$-acetate, the other contained $40 \mathrm{~mm}$-thiosulphate; total cell number $1.6-1.8 \times 10^{9}$ cells $\mathrm{ml}^{-1}$. (b) One medium contained $2.2 \mathrm{mM}$-acetate plus $34.4 \mathrm{mM}$-thiosulphate (I), the other contained $10 \mathrm{~mm}$-thiosulphate plus $6.4 \mathrm{~mm}$ acetate (II) (see also Table 1); total cell number $2 \cdot 0-2 \cdot 1 \times 10^{9}$ cells $\mathrm{ml}^{-1}$. (c) One medium contained $5.7 \mathrm{~mm}$-acetate plus $31.0 \mathrm{~mm}$-thiosulphate (III), the other contained $6.0 \mathrm{~mm}$-thiosulphate plus $11.7 \mathrm{~mm}$-acetate (IV) (see also Table 1); total cell number $2.2-2.6 \times 10^{9} \mathrm{cells} \mathrm{m}^{-1}$.

Thiobacillus A2 was able to compete successfully with both $T$. neapolitanus and spirillum G7, depending on the substrate ratio in the reservoir medium (Table 1). Therefore the question was raised whether this would still be true if different mixtures of thiosulphate and acetate were supplied alternately to the three-membered culture. This was investigated in the following experiments. At first, two media were employed which contained $34.4 \mathrm{mM}$ thiosulphate plus $2.2 \mathrm{~mm}$-acetate (I in Table 1 and Fig. 5) and $10 \mathrm{mM}$-thiosulphate plus 6.4 mM-acetate (II). Alternate feeding of these two media, each during a period of $4 \mathrm{~h}$ at a dilution 
Table 1. Composition of three-membered mixed cultures of Thiobacillus A2, spirillum G7 and $T$. neapolitanus after growth in a chemostat with various concentrations of acetate and thiosulphate in the feed

The data are taken from Gottschal et al. (1979). The cultures were grown for approximately 10 volume changes at a dilution of $0.05 \mathrm{~h}^{-1}$ with acetate and thiosulphate supplied continuously together at the concentrations shown.

$\begin{array}{ccc}\text { Thiosulphate } & \text { Acetate } & \\ 40 \cdot 0 & 0 & \\ 34 \cdot 4 & 2 \cdot 2 & \text { (I) } \\ 35 \cdot 0 & 2 \cdot 5 & \\ 31 \cdot 0 & 5 \cdot 7 & \text { (III) } \\ 25 \cdot 0 & 7 \cdot 5 & \\ 10 \cdot 0 & 6 \cdot 4 & \text { (II) } \\ 15 \cdot 0 & 12 \cdot 5 & \\ 6 \cdot 0 & 11 \cdot 7 & \text { (IV) } \\ 5 \cdot 0 & 17 \cdot 5 & \\ 0 & 20 \cdot 0 & \end{array}$

Thiosulphate/
acetate ratio

$\infty$
$15 \cdot 6$
$14 \cdot 0$
$5 \cdot 44$
$3 \cdot 33$
1.56
1.20
0.51
0.29
0

$\overbrace{\begin{array}{c}\text { Thiobacillus } \\ \mathrm{A} 2\end{array}}^{\begin{array}{c}\text { Spirillum } \\ \mathrm{G} 7\end{array}} \begin{gathered}\begin{array}{c}\text { Thiobacillus } \\ \text { neapolitanus }\end{array} \\ \text { Percentage of total cell no. }\end{gathered}$

* The numbers I-IV denote the combinations of thiosulphate and acetate used in the experiments shown in Fig. $5(b, c)$ with alternating supply of different mixtures of thiosulphate and acetate.

rate of $0.05 \mathrm{~h}^{-1}$, resulted in a gradual washout of Thiobacillus A2 during the first 12 volume changes $(240 \mathrm{~h})$, but after this initial period the culture composition remained unchanged, with Thiobacillus A2 accounting for $15 \%$ of the total cell number (Fig. $5 b$ ). In the next experiment, the composition of the two media used [ $31 \mathrm{mM}$-thiosulphate plus $5.7 \mathrm{~mm}$-acetate (III) and $6 \mathrm{mM}$-thiosulphate plus $11.7 \mathrm{mM}$-acetate (IV)] appeared even more favourable for growth of Thiobacillus A2, since after 26 volume changes $(520 \mathrm{~h})$ this organism clearly dominated the two specialized bacteria. This latter result seems consistent with the fact that the composition of the media used in this case (III and IV) also allowed more successful competition of Thiobacillus A2 with $T$. neapolitanus and spirillum G7 during continuous supply of either one of these media (Table 1).

\section{Enrichment of a facultatively chemolithotrophic thiobacillus during alternating autotrophic and heterotrophic growth conditions}

Though the above results demonstrated that alternate autotrophic and heterotrophic growth conditions were rather unfavourable for Thiobacillus A2 (Fig. 5 a), they did not exclude the possibility that other facultative chemolithotrophs might occur in nature which could successfully compete with more specialized species under such growth conditions. In an attempt to find an answer to this question, an enrichment experiment was performed in a chemostat to which acetate and thiosulphate were supplied intermittently as growth-limiting substrates, each during $4 \mathrm{~h}$.

The sample used as inoculum for the enrichment culture was obtained from a freshwater habitat from which obligately and facultatively chemolithotrophic thiobacilli and (thiosulphate-oxidizing) heterotrophs had been isolated previously (Gottschal \& Kuenen, $1980 \mathrm{a}$ ). At first, unrestricted growth was allowed to occur on a mixture of thiosulphate $(6.5 \mathrm{mM})$ and acetate $(6 \mathrm{mM})$ until both substrates had been utilized completely. At the end of this period $(2 \mathrm{~d})$, alternate feeding of acetate $(10 \mathrm{mM})$ and thiosulphate $(40 \mathrm{mM})$ was started, initially at a low dilution rate of $0.01 \mathrm{~h}^{-1}$. This rate was gradually increased until a dilution rate of $0.05 \mathrm{~h}^{-1}$ was established, while care was taken to avoid more substrate being fed to the culture than could actually be metabolized. After 12, 20 and 30 volume changes (240, 
Table 2. Results of enrichment culture after various numbers of volume changes in the chemostat under alternate acetate and thiosulphate limitation, each during $4 h$, at a dilution rate of $0.05 \mathrm{~h}^{-1}$

\begin{tabular}{|c|c|c|c|c|c|c|c|}
\hline \multirow{2}{*}{$\begin{array}{l}\text { No. of } \\
\text { volume } \\
\text { changes }\end{array}$} & \multirow{2}{*}{$\begin{array}{c}10^{-8} \times \\
\text { Total cell } \\
\text { no. } \mathrm{ml}^{-1}\end{array}$} & \multicolumn{3}{|c|}{ Percentage of total cell no. } & \multirow[b]{2}{*}{$A_{433}$} & \multirow{2}{*}{$\begin{array}{l}\text { Protein } \\
\text { content } \\
\left(\mathrm{mg} \mathrm{l}^{-1}\right)\end{array}$} & \multirow{2}{*}{$\begin{array}{l}\text { Organic cell } \\
\text { carbon } \\
\text { content } \\
\left(\mathrm{mg} \mathrm{l}^{-1}\right)\end{array}$} \\
\hline & & Spirillum & Short rod & Other & & & \\
\hline 12 & $6 \cdot 8$ & 20 & 68 & 12 & 0.40 & 64 & 50 \\
\hline 20 & $7 \cdot 6$ & 27 & 54 & 19 & 0.47 & 95 & 76 \\
\hline 30 & $4 \cdot 5$ & 42 & 31 & 27 & 0.47 & 100 & 77 \\
\hline
\end{tabular}

400 and $600 \mathrm{~h}$ ) the composition of the mixed culture was determined by colony plate counting on different media (see Methods) and by cell density measurements. The results (Table 2) indicated that a small rod and a spirillum-shaped organism had become dominant in the mixed culture. Furthermore, it was obvious that the culture was rather heterogeneous even after 30 volume changes. The total cell number relative to the observed protein and organic cell carbon content of the culture was low as compared to a culture of Thiobacillus A2 under the same growth conditions $\left(1.6 \times 10^{9}\right.$ Thiobacillus A2 cells per $0.120 \mathrm{mg}$ protein). This was not caused by a low viability of the culture, since viability appeared to be $85 \%$ or more. It might be explained by the marked tendency of the culture to form small clumps of bacteria, which resulted in a considerable underestimation of the number of individual cells.

Preliminary experiments aimed at determining the physiological properties of the two dominant species indicated that the spirillum-shaped organism was a facultatively chemolithotrophic Thiobacillus-like or Thiomicrospira-like organism. The rod-shaped bacterium grew only heterotrophically, but in addition appeared to be able to oxidize thiosulphate. Repeated colony transfers from thiosulphate-containing to acetate-containing agar media and back again confirmed that the spirillum-shaped organism represented one organism and not a mixture of heterotrophs and chemolithotrophic bacteria. Both in liquid culture and on thiosulphate agar $\mathbf{S}^{0}$ was formed, which in batch culture was further oxidized to sulphate. It appeared that the spirillum-shaped organism required a growth factor, both for growth on acetate and for growth on thiosulphate. This requirement could be satisfied by the addition of $0.005 \%$ yeast extract to the medium. An interesting observation was that the spirillum-shaped organism retained a low level of thiosulphate-oxidizing capacity even after prolonged growth on acetate.

\section{DISCUSSION}

The experiments described in this paper clearly showed that Thiobacillus A2 is able to grow alternately autotrophically and heterotrophically in the chemostat at a rate of $0.05 \mathrm{~h}^{-1}$. Nevertheless it appeared that the ability to grow uninterrupted under such growth conditions was definitely dependent on the frequency and the duration of the periods of autotrophic and heterotrophic growth. A long period of acetate-limited growth relative to that of thiosulphate-limited growth caused too extensive loss of the autotrophic potential to allow an immediate resumption of growth at the required rate of $0.05 \mathrm{~h}^{-1}$ upon the transition from acetate limitation to thiosulphate limitation (Fig. 1a). In contrast, conditions in which relatively short periods of acetate-limited growth alternated with long periods of growth under thiosulphate limitation (Fig. $1 b$ ) allowed undisturbed growth at a constant rate. This is not surprising in the light of what is known about the regulation of the heterotrophic and autotrophic metabolism in Thiobacillus A2 (Gottschal \& Kuenen, 1980 b; Gottschal et al., 1981). Enzymes required for heterotrophic growth have been shown to remain always present at a sufficient level to allow growth at a rate of at least $0.05 \mathrm{~h}^{-1}$, even in steady-state 
chemostat cultures under thiosulphate limitation (Gottschal \& Kuenen, $1980 \mathrm{~b}$; Gottschal et al., 1981). However, two crucial metabolic capacities required for autotrophic growth on thiosulphate, namely the ability to oxidize thiosulphate and the ability to fix bicarbonate, have been shown to disappear completely during prolonged heterotrophic growth (Gottschal \& Kuenen, $1980 b$; Gottschal et al., 1981). In the present study, the rates of synthesis and inactivation observed (Figs 1 and 2) were very similar to those reported earlier (Gottschal et al., 1981).

In a previous report it was shown that Thiobacillus A2 grown in two-membered mixed culture, under acetate or thiosulphate limitation, with the heterotrophic spirillum G7 or the obligate chemolithotrophic $T$. neapolitanus, was completely outcompeted (Gottschal et al., 1979). In contrast, the outcome of the two-membered cultures described in the present study indicated that growth under alternate acetate and thiosulphate limitation allowed Thiobacillus A2 to compete successfully with the heterotroph and to coexist with $T$. neapolitanus (Figs 3 and 4). This difference might be explained by the manner in which the acetate and thiosulphate metabolism of Thiobacillus A2 is regulated. The organism retains the ability to metabolize acetate and to grow on it without a lag during autotrophic growth on thiosulphate, but completely represses the potential to oxidize thiosulphate and to fix $\mathrm{CO}_{2}$ during growth on acetate (Gottschal \& Kuenen, $1980 b$; Gottschal et al., 1981). In a mixed culture of Thiobacillus A2 and spirillum G7 (with alternate supply of acetate and thiosulphate), this property would allow Thiobacillus A2 to metabolize a substantial amount of the available acetate, with the result that growth of spirillum G7 during the acetate-limited periods was insufficient to compensate for the loss of cells during the periods of thiosulphate limitation. On the other hand, the observed coexistence of Thiobacillus A2 and T. neapolitanus grown in a mixed culture under alternate acetate and thiosulphate limitation indicated that Thiobacillus A2 did not grow significantly at the expense of thiosulphate, probably as a result of repression of the potential to fix $\mathrm{CO}_{2}$ and to oxidize thiosulphate. Such a repression of the autotrophic potential obviously took place during the acetate-limited period (Fig. 2), but probably also occurred to a certain extent during the period of thiosulphate limitation because of the excretion of glycollate by $T$. neapolitanus (Cohen et al., 1979; Gottschal et al., 1979). In other words, Thiobacillus A2 was forced to grow mainly as a heterotroph (on acetate) thereby allowing $T$. neapolitanus to metabolize virtually all the thiosulphate.

This conclusion may also provide an explanation for the observed inability of Thiobacillus A2 to maintain itself in the three-membered culture with an alternate supply of thiosulphate and acetate (Fig. 5a). Given the fact that Thiobacillus A2 grows as a heterotroph in such a mixed culture, thiosulphate is used by $T$. neapolitanus alone, whereas spirillum $\mathrm{G} 7$ and Thiobacillus A2 compete for the available acetate. Furthermore, since it was shown in a previous study (Gottschal et al., 1979) that the heterotroph outcompeted Thiobacillus A2 in mixed cultures grown under acetate limitation, it must be concluded that Thiobacillus A2 will eventually be eliminated from a three-membered culture grown under alternate acetate and thiosulphate limitation. Yet, when Thiobacillus A2 was not forced to grow alternately heterotrophically and autotrophically, but instead could grow mixotrophically, limited alternately by two different mixtures of acetate and thiosulphate (Fig. $5 b, c$ ), coexistence with the two specialized organisms was observed. This result once more underlined the selective advantage of mixotrophic growth for a facultatively chemolithotrophic Thiobacillus (Gottschal et al., 1979; Gottschal \& Kuenen, 1980a).

Although Thiobacillus A2 was eliminated from the three-membered mixed cultures when grown under alternating acetate and thiosulphate limitation, a spirillum-shaped facultatively chemolithotrophic Thiobacillus or Thiomicrospira became dominant in an enrichment culture grown under the same conditions (Table 2). The most simple, and in our opinion most attractive, explanation for the difference between the outcome of this enrichment culture and our three-membered mixed cultures is that the facultatively chemolithotrophic spirillum possesses some metabolic features which make it better adapted to alternating growth 
conditions than our model organism Thiobacillus A2. Speculating on the nature of these properties, it seems likely that this spirillum should show a less rapid loss than Thiobacillus A2 of its potential to oxidize thiosulphate and to fix $\mathrm{CO}_{2}$, and should never lose this potential completely. A physiological study on the properties of this organism is in progress, and preliminary results have confirmed that the thiosulphate-oxidizing capacity is not repressed completely during heterotrophic growth.

It should be stressed here that the results reported above of the enrichment and of the competition experiments were obtained at the same dilution rate, with one regime of substrate alternations. Similar enrichment experiments using samples from a marine environment appeared unsuccessful (J. G. Kuenen, unpublished), as were enrichment experiments in which acetate and thiosulphate were supplied simultaneously to a continuous culture (Gottschal \& Kuenen, $1980 a$ ). It will be obvious that other combinations of dilution rate and substrate alternations might yield quite different results. Although this can be studied experimentally, we believe that this kind of problem is very well suited to a mathematical approach.

The alternating growth conditions employed in this study will probably not be found in the natural environment, at least not with such regularity as in our experiments. Nevertheless, a strongly fluctuating nutrient supply will probably be the rule rather than the exception in many environments. It might be concluded from the present investigation that facultatively chemolithotrophic thiobacilli of the type of Thiobacillus A2 are not particularly suited for growth under such conditions, but rather are specialized in growing under conditions of a simultaneous supply of inorganic and organic compounds (Gottschal et al., 1979). On the other hand there seems to exist, in addition, another type of facultative chemolithotroph far more suited for growth under fluctuating environmental conditions.

\section{REFERENCES}

Cohen, Y., DE Jonge, I. \& Kuenen, J. G. (1979). Excretion of glycolate by Thiobacillus neapolitanus grown in continuous culture. Archives of Microbiology 122, 189-194.

GotTsChal, J. C. \& Kuenen, J. G. (1980a). Selective enrichment of facultatively chemolithotrophic thiobacilli and related organisms in continuous culture. FEMS Microbiology Letters 7, 241-247.

Gottschal, J. C. \& Kuenen, J. G. (1980b). Mixotrophic growth of Thiobacillus $A 2$ on acetate and thiosulfate as growth limiting substrates in the chemostat. Archives of Microbiology 126, 33-42.

Gottschal, J. C., De VRies, S. \& Kuenen, J. G. (1979). Competition between the facultatively chemolithotrophic Thiobacillus A2, an obligately chemolithotrophic Thiobacillus and a heterotrophic spirillum for inorganic substrates. Archives of Microbiology 121, 241-249.

Gottschal, J. C., Pol, A. \& Kuenen, J. G. (1981). Metabolic flexibility of Thiobacillus $A 2$ during substrate transitions in the chemostat. Archives of Microbiology 129, 23-28.
Harder, W., Visser, K. \& Kuenen, J. G. (1974). Laboratory fermenter with an improved magnetic drive. Laboratory Practice 23, 644-645.

KueneN, J. G. \& VeldKamp, H. (1973). Effects of organic compounds on growth of chemostat cultures of Thiomicrospira pelophila, Thiobacillus thioparus and Thiobacillus neapolitanus. Archives of Microbiology 94, 173-190.

Postgate, J. R. (1969). Viable counts and viability. Methods in Microbiology 1, 611-628.

Smith, A. L. \& Kelly, D. P. (1979). Competition in the chemostat between an obligately and a facultatively chemolithotrophic Thiobacillus. Journal of General Microbiology 115, 377-384.

TAYLOR, B. F. \& HOARE, D. S. (1969). New facultative Thiobacillus and a reevaluation of the heterotrophic potential of Thiobacillus novellus. Journal of Bacteriology 100, 487-497.

Vishniac, W. \& SANTER, M. (1957). The thiobacilli. Bacteriological Reviews 21, 195-213. 